\title{
The Economic Burden of Urinary Tract Infection and Pressure Ulceration in Acute Traumatic Spinal Cord Injury Admissions: Evidence for Comparative Economics and Decision Analytics from a Matched Case-Control Study
}

\author{
Barry A.B. White, Nicolas Dea, John T. Street, ${ }^{3}$ Christiana L. Cheng,, Carly S. Rivers, \\ Najmedden Attabib,' Brian K. Kwon, Charles G. Fisher, and Marcel F. Dvorak ${ }^{3}$
}

\begin{abstract}
Secondary complications of spinal cord injury (SCI) are a burden to affected individuals and the rest of society. There is limited evidence of the economic burden or cost of complications in SCI populations in Canada, however, which is necessary for comparative economic analyses and decision analytic modeling of possible solutions to these common health problems. Comparative economic analyses can inform resource allocation decisions, but the outputs are only as good as the inputs. In this article, new evidence of the excess or incremental costs of urinary tract infection (UTI) and pressure ulceration (PU) in acute traumatic SCI from an exploratory case series analysis of admissions to a Level I specialized Canadian spine facility (20082013) is presented. Participants in a national SCI registry were case-control matched (1:1) on the predicted probability of experiencing UTI or PU during initial acute SCI admission. The excess costs of UTI and PU are estimated as the mean of the differences in total direct acute SCI admission costs (length of stay, accommodation, nursing, pharmacy) from the perspective of the admitting facility between participants matched or paired on demographic and SCI characteristics. Even relatively minor UTI and PU, respectively, added an average of \$7,790 (standard deviation [SD] \$6,267) and \$18,758 (SD \$27,574) to the direct cost of acute SCI admission in 2013 Canadian dollars (CAD). This case series analysis established evidence of the excess costs of UTI and PU in acute SCI admissions, which will support decision-informing analyses in SCI.
\end{abstract}

Keywords: economic burden; pressure ulcers; secondary complications; spinal cord injury; urinary tract infections

\section{Introduction}

$\mathbf{T}$ HE IMPAIRMENT AND DISABILITY resulting from acute spinal cord injury (SCI) has tremendous immediate and long-term consequences for injured persons, their family members, and the rest of society. Consequences include the perpetual risk of secondary complications because of the chronic health conditions caused by long-standing neurological deficits. Persons with SCI are susceptible particularly to complications such as urinary tract infection (UTI), pressure ulceration (PU), pneumonia, neuropathic pain, and thromboembolisms from the onset of SCI through the rest of their lives. ${ }^{1-12}$ In acute SCI populations, the reported incidence of secondary complications ranges from $44 \%$ to $77 \%,{ }^{13-19}$ and the proportion of individuals with a SCI ever experiencing a complication in their lifetime is reported to be as high as $95 \% .^{20-26}$

Two of the more common secondary complications in acute SCI admissions are UTI and PU. In a population of acute traumatic SCI admissions to a Level I specialized spine facility in British Columbia, Canada, up to $43 \%$ of individuals experienced $\mathrm{UTI}^{27}$ and $15 \%$ experienced PU. ${ }^{18}$ These reported incidences may suggest a demand for innovation in the prevention and management of hospitalacquired UTI and PU in the acute SCI population in Canada, but there is limited evidence to determine the extent of the demand.

Secondary complications of SCI, including UTI and PU, are believed to be a central determinant of health-related well-being and healthcare utilization beyond the initial consequences of SCI. The

\footnotetext{
${ }^{1}$ Rick Hansen Institute, Vancouver, British Columbia, Canada.

${ }^{2}$ Service de Neurochirurgie, Université de Sherbrooke, Sherbrooke, Québec, Canada.

${ }^{3}$ Vancouver Spine Surgery Institute, Department of Orthopaedics, University of British Columbia, Vancouver, British Columbia, Canada

${ }^{4}$ Dalhousie University, Halifax, Nova Scotia; Horizon Health Network, Division of Neurosurgery, Saint John Regional Hospital, Saint John, New Brunswick, Canada.

(C) Barry A.B. White et al., 2017; Published by Mary Ann Liebert, Inc. This Open Access article is distributed under the terms of the Creative Commons Attribution Noncommercial License (http://creativecommons.org/licenses/by-nc/4.0/) which permits any noncommercial use, distribution, and reproduction in any medium, provided the original author(s) and the source are credited.
} 
possible causes of UTI and PU, other than impaired mobility, sensation, and other physiological changes associated with SCI, are not fully understood. It is undeniable, however, that secondary complications of SCI during the initial hospital stay (hospital-acquired) or after discharge into the community (community-acquired) can increase the complexity of care and lead to significant human and economic costs. Complications in the acute phase of care may result in increased hospital length of stay (LOS), invasive or complex treatment(s), and predispose individuals to recurrence and development of further complications in the rehabilitation and community phases of care. ${ }^{16,18}$ After return to community-living, the consequences of complications may include excess use of ambulatory healthcare services, hospitalization, out-of-pocket expenses, lost employment earnings, limitations on activities of daily living, reductions in healthrelated quality of life, and in some cases death. ${ }^{2,10,18}$ Moreover, the value of forgone health benefits on account of the treatment and management of preventable secondary complications of SCI in all phases of care may represent significant opportunity costs.

Despite alarming rates of complications in SCI populations across the care continuum or over the lifetime of the individual ${ }^{16,18,19,28-33}$ and the impact on individuals and their family members, empirical evidence of the economic burden (or the potential cost avoidance associated with a reduction in the incidence and/or severity) of complications of SCI is limited. Of the two Canadian-based studies published more recently, one reported that the average excess cost of peri-operative adverse events or secondary complications after spinal surgical procedures ranged from less than $\$ 5000$ for grade 1 complications (least severe) to more than $\$ 120,000$ for grade 3 and 4 complications (most severe); the excess cost of particular acute SCI complications was not the primary focus of the analysis. The other study examined the cost of PU in a small number of individuals with SCI living in the community. ${ }^{34}$ The average cost to manage community-acquired PU was estimated to be approximately $\$ 4700$ per month; however, the variability in monthly cost was found to be large, and limitations including the data collection period are believed to have resulted in conservative estimates.

Although evidence from alternative populations (e.g., SCI populations outside of Canada and general healthcare consumer populations in Canada) may lead to the establishment of reasonable assumptions for assessment of solutions to health problems in the Canadian SCI context, understanding of the problem in a particular context is believed to be important for appropriate assessment of the costs and consequences of relevant solutions. The existing evidence, on which assumptions will be based in the absence of further research involving SCI populations in Canada, has been established largely in general hospital or SCI populations in the United States. Because healthcare costs in Canada and the United States are different, existing evidence may not be generalizable to SCI populations in Canada. ${ }^{35-37}$ Further, existing evidence is limited in that it is commonly based on the association between hospital-acquired complications and hospital LOS, or community-acquired complications and the probability and duration of hospital readmission.

A recent review published by SCI Rehabilitation Evidence presents limitations in terms of evidence of the burden of SCI and the consequent paucity of high-quality comparative economic analyses of possible solutions to the burden of SCI. ${ }^{38}$ Further evidence of the burden of secondary complications in SCI populations in Canada will enhance the breadth, quality, and relevancy of comparative economic analyses of solutions to the excess burden of secondary complications of SCI in the Canadian context. In turn, this information can enhance resource allocation decisions ultimately affecting the lives of persons living with SCI in Canada.
Although the context is believed to be important in assessing the costs and consequences of solutions, the establishment of an appropriate decision analytic or economic model in one context can inform important efforts in other contexts.

This article describes a retrospective case series analysis to establish evidence of the excess cost associated with two common secondary complications in acute traumatic SCI admissions in Canada-UTI and PU. This article does not present clinical or costeffectiveness evidence; rather, it provides new information on the economic burden of UTI and PU to support decision-informing economic analyses and value for money considerations in SCI. Specifically, this work will support comparative economic analyses and decision analytic modeling in SCI.

\section{Methods}

\section{Data compilation}

Case series participants were selected from the Rick Hansen SCI Registry (RHSCIR), a prospective observational registry of adults with new traumatic SCI who were admitted to a participating Level I specialized spine facility in Vancouver, British Columbia, Canada (now referred to as the study site). ${ }^{39}$ Local research ethics board approval was obtained before enrollment in the RHSCIR. Registry enrollment and privacy requirement are described elsewhere. ${ }^{39,40}$ The larger population of traumatic and non-traumatic SCI admissions to the study site during alternative periods along with respective incidences of common complications are also described elsewhere. $^{18,19,29,31,32}$

The case series was restricted to participants admitted to the study site within $48 \mathrm{~h}$ of injury to avoid potential confounders associated with delayed admission to specialized care, which has been shown to increase the risk of secondary complications. ${ }^{41,42}$ The case series was further restricted to participants age 19 and older at admission, because too few RHSCIR participants were age 16 to 18 to expect reasonable matches on demographic and SCI characteristics. Further details on the selection and arrangement of the case series analysis cohort are provided below.

The age at time of SCI (10 year age intervals), gender, neurologic classification at admission using the International Standards for Neurological Classification of Spinal Cord Injury (ISNCSCI) examination, ${ }^{43}$ including American Spinal Injury Association (ASIA) Impairment Scale (AIS A, B, C, D), initial total motor score, neurological level (high cervical, C1-C4; low cervical, C5-T1; thoracic/ thoracolumbar, T2-L2), neurology (complete, AIS A; incomplete, AIS B, C, D), and acute LOS were extracted from the RHSCIR. The RHSCIR also includes information on specific hospital-acquired complications (e.g., UTI and PU) recorded using the Spine Adverse Events Severity (SAVES) ${ }^{19}$ instrument for each participating acute SCI admission to the study site. The RHSCIR and the development and application of the validated SAVES instrument are described in detail elsewhere. ${ }^{19,39,44,45}$

\section{Case series analysis}

Separate analyses were performed to examine the excess cost of UTI and PU in traumatic SCI admissions from the perspective of the study site. Like previous analyses of the excess cost of hospitalacquired complications, ${ }^{46-49}$ a matched case-control methodology was used to estimate the hospital cost associated with UTI and PU in admissions to the study site. The methodology and focus on UTI and PU were determined in consideration of the limited number of observations for which the study site agreed to provide basic costing information (a maximum of 50 participants) and to minimize the influence of confounding variables. The excess costs of UTI and PU are estimated as the mean of the differences in total direct acute SCI admission costs between matched or paired case series participants 
who differed with regard to UTI or PU during acute SCI admission. Descriptive statistics were used to summarize the results. The small sample size prevented statistical analyses and subgroup analyses.

\section{Analysis cohort}

Before matching on observed demographic and SCI characteristics, four mutually exclusive groups of eligible RHSCIR participants were defined using the SAVES data:

(1) UTI Group-experienced one or more UTI and no other documented complications.

(2) No Complication Group-experienced no documented complications.

(3) PU Group-experienced one or more PU.

(4) No PU Group — did not experience a documented PU.

The matching process for the UTI cost analysis was limited to RHSCIR participants with no other secondary complications to avoid attributing the cost of other complications to the cost of UTI in acute SCI admissions. Participants assigned to the PU Group and No PU Group commonly experienced other documented complications during their acute hospital stay. Other secondary complications were considered in the matching process for the PU cost analysis, but not the UTI cost analysis.

After initial stratification (i.e., hard matching) by neurological AIS classification and neurology, eligible RHSCIR participants assigned to the UTI Group $(n=19)$ were matched with participants assigned to the No Complication Group $(n=77)$, and participants assigned to the PU Group $(n=22)$ were matched with participants assigned to the No PU Group $(n=239)$ based on propensity or predicted probability of experiencing UTI or PU, respectively. For the UTI and PU analyses, individual propensity scores were estimated using logit regressions conditional on age at time of SCI, gender, initial motor score, and neurological level in strata of sufficient size. As mentioned, incidence of other SAVES documented post-operative complications (i.e., UTI, pneumonia, delirium, one and two or more other complications) were also included in the estimation of PU propensity scores. A separate matching process was performed for individuals in the UTI Group and individuals in the PU Group. Logit regression estimation and 1:1 matching were performed using STATA 13 and the psmatch 2 command. ${ }^{50}$

After identifying the individuals in the No Complication Group who best matched the 19 individuals in the UTI Group, and the individuals in the No PU Group who best matched the 22 individuals in the PU Group, the 25 pairs exhibiting the smallest difference in propensity scores were selected. The selected pairs included 10 participants in the UTI Group, 15 participants in the PU Group, and their respective best matches. Nearly all 25 selected pairs exhibited reasonable closeness based on the demographic and SCI characteristics included in the regression models.

The study site used an internal costing formula to calculate the direct cost of acute SCI admission for the agreed number of case series participants. The internal costing formula was based largely on acute LOS, documented transitions between hospital units, and respective unit daily cost assumptions (accommodation, nursing, and pharmacy) for 2013/2014 fiscal internal planning purposes. The results are presented in current (or unadjusted) 2013 CAD. For comparison, all other estimates discussed have been converted to 2013 CAD using Purchasing Power Parity and Statistics Canada's Consumer Price Index for Health and Personal Care. ${ }^{51,52}$

\section{Results}

\section{Analysis cohort}

The case matching processes resulted in 10 and 15 pairs in terms of the predicted probability of UTI and PU, respectively. Two pairs were excluded from the PU cost analysis, however, because the difference in the predicted probability of PU between pairs was considerably greater than the difference between the other pairs. Although there is no agreement on an acceptable difference in the propensity scores of matched participants, ${ }^{53}$ the decision to exclude the two pairs exhibiting a propensity score difference of more than 0.20 was made to minimize confounding effects in the limited data and avoid overestimating the cost of PU. For these two pairs, differences in propensity scores appeared to be due to differences in experiences with other secondary complications. In addition, although the difference in propensity scores was reasonable, one pair was excluded because of data identified as extreme outliers (discussed further below). This left a total cohort of 44 participants, or 22 pairs, consisting of 10 pairs who differed with regard to development of hospital-acquired UTI, and 12 pairs who differed with regard to hospital-acquired PU.

The average age of the case series of 44 participants at time of SCI was 42 years; approximately $77 \%$ are male, $73 \%$ sustained a cervical SCI, and 55\% had incomplete injuries at initial assessment. Demographic and SCI characteristics by group assignment are presented in Table 1. For the 20 participants included in the UTI cost analysis, the mean acute hospital LOS was estimated to be 18.4 days (standard deviation [SD] 8.1 days). The estimated average total direct cost of acute SCI admission for the 20 paired participants was $\$ 19,171$ (SD \$9171). For the 24 participants included in the PU cost analysis, the mean LOS was 41.4 days (SD 25.3 days), and the estimated average total direct cost was $\$ 49,806$ (SD \$32,723). Mean LOS and SCI admission cost by group assignment as well as the estimated mean of the differences in acute hospital LOS and costs between paired participants are presented in Table 2.

\section{Hospital-acquired UTI}

Exact or near exact matches, based on the stated criteria, were found for 10 participants assigned to the UTI Group. The difference between the 10 pairs from the UTI and No Complication Groups in the predicted probability of a hospital-acquired UTI was less than 0.01 . The difference in LOS ranged from one to 16 days. The mean difference in acute hospital LOS between pairs in the UTI cost analysis was 6.8 days (SD 5.0 days; $95 \%$ confidence interval $[\mathrm{CI}] 3.2-10.4$ days), and the mean difference in total acute SCI admission costs was $\$ 7790$ (SD $\$ 6267 ; 95 \%$ CI \$3307-\$12,273) (Table 2). All UTI occurrence included in the cost analysis were described as complications necessitating minor noninvasive treatment with no long-term effects.

\section{Hospital-acquired PU}

The difference in the predicted probability of hospital-acquired PU was less than 0.02 for 11 of the selected pairs and 0.15 for the twelfth pair from the PU and No PU Groups, indicating reasonable matches on the characteristics included in the regression model. Hospital LOS ranged from 16 to 105 days in the PU Group and five to 70 days in the No PU Group. The difference in LOS between pairs ranged from 16 fewer to 59 additional days, and the mean difference was 15.8 days (SD 19.9 days; 95\% CI 3.1-28.4). The mean difference in total acute SCI admission costs between paired participants in the PU cost analysis was $\$ 18,758$ (SD \$27,574; $95 \%$ CI \$1239-\$36,277) (Table 2). Although National Pressure Ulcer Advisory Panel (NPUAP) PU category data were not reviewed, the 12 paired participants in the PU Group experienced PU necessitating minor noninvasive treatment with no long-term effects, representative of less severe NPUAP category I or II PU. ${ }^{54}$ 
Table 1. Characteristics and Experiences of Matched or Paired Rick Hansen Spinal Cord Injury Registry Participants Assigned to the Urinary Tract Infection, No Complication, Pressure Ulceration, and No Pressure Ulceration Groups by Case Series Group Assignment

\begin{tabular}{|c|c|c|c|c|c|c|}
\hline & \multicolumn{3}{|c|}{ UTI analysis } & \multicolumn{3}{|c|}{ PU analysis } \\
\hline & $U T I(\mathrm{n}=10)$ & No Comp $(\mathrm{n}=10)$ & $d$ & $P U(\mathrm{n}=12)$ & No $P U(\mathrm{n}=12)$ & $d$ \\
\hline \multicolumn{7}{|l|}{ Strict or hard matched characteristics } \\
\hline AIS A & 30.0 & 30.0 & 0.00 & 58.3 & 58.3 & 0.00 \\
\hline AIS B & 20.0 & 20.0 & 0.00 & 25.0 & 25.0 & 0.00 \\
\hline AIS C or D & 50.0 & 50.0 & 0.00 & 16.7 & 16.7 & 0.00 \\
\hline \multicolumn{7}{|l|}{ Neurology of SCI, \% } \\
\hline Incomplete (AIS B, C, D) & 70.0 & 70.0 & 0.00 & 41.7 & 41.7 & 0.00 \\
\hline Complete (AIS A) & 30.0 & 30.0 & 0.00 & 58.3 & 58.3 & 0.00 \\
\hline \multicolumn{7}{|c|}{ Propensity score estimation characteristics } \\
\hline Gender male, $\%$ & 60.0 & 60.0 & 0.00 & 83.3 & 100.0 & 0.99 \\
\hline Age at time of SCI, mean (SD) & $43.2(22.7)$ & $44.9(15.4)$ & 0.09 & $41.9(18.4)$ & $36.5(21.3)$ & 0.27 \\
\hline Initial motor score, mean (SD) & $52.7(15.9)$ & $53.3(20.3)$ & 0.03 & $26.4(26.6)$ & $36.6(28.4)$ & 0.37 \\
\hline \multicolumn{7}{|l|}{ Neurological level, \% } \\
\hline High cervical (C1-C4) & 30.0 & 30.0 & 0.00 & 25.0 & 25.0 & 0.00 \\
\hline Low cervical (C5-T1) & 20.0 & 20.0 & 0.00 & 75.0 & 58.3 & 0.42 \\
\hline Thoracic/Thoracolumbar (T2-L2) & 50.0 & 50.0 & 0.00 & 0.0 & 16.6 & 0.99 \\
\hline \multicolumn{7}{|l|}{ Other acute secondary complications, \% } \\
\hline UTI & N/A & N/A & N/A & 66.7 & 75.0 & 0.22 \\
\hline Pneumonia & N/A & N/A & N/A & 66.7 & 66.7 & 0.00 \\
\hline Delirium & N/A & N/A & N/A & 16.7 & 8.3 & 0.43 \\
\hline 1 other complication & N/A & N/A & N/A & 33.3 & 33.3 & 0.00 \\
\hline 2 or more other complications & N/A & N/A & N/A & 50.0 & 41.7 & 0.19 \\
\hline
\end{tabular}

UTI, urinary tract infection; PU, pressure ulceration; $d$, standardized mean-difference; ASIA, American Spinal Injury Association; SCI, spinal cord injury; SD, standard deviation; N/A, not applicable; No Comp, no complications.

\section{Excluded outlying pair}

As mentioned above, a pair was excluded from the PU cost analysis because the differences in LOS (221 days vs. 13 days) and SCI admission costs $(\$ 226,714$ vs. $\$ 12,074)$ were identified as extreme outliers. The outlying pair was the only pair in which the PU was described as a complication necessitating invasive or complex treatment such as a surgical procedure or monitoring in the intensive care unit and, considering the limited number of pairs in the analysis, inclusion of the pair would have resulted in a near doubling of the cost of hospital-acquired PU in acute SCI admissions. Although it may be correct to assume that one in every 13 or so PU occurrence at the study site will require invasive or complex treatment, data limitations prevented inclusion of the outlying pair. The implications are discussed, however, and help illustrate a limitation of the analysis as well as a fundamental consideration for economic and decision analytic modeling in SCI.

\section{Discussion}

The case series analysis established new evidence of the excess costs of hospital-acquired UTI and hospital-acquired PU in SCI admissions to the Level I specialized spine facility. The estimated excess cost of UTI requiring only minor noninvasive treatment in SCI admissions in the case series (\$7790) is relatively consistent with the reported excess cost of minor secondary complications

Table 2. Summary of Acute Spinal Cord Injury length Of Stay and Hospital Costs for Matched or Paired Case Series Participants by Group Assignment and Estimated Mean Differences between Pairs

\begin{tabular}{|c|c|c|c|c|c|c|}
\hline & \multicolumn{3}{|c|}{ UTI analysis } & \multicolumn{3}{|c|}{$P U$ analysis } \\
\hline & $U T I(\mathrm{n}=10)$ & No Comp $(\mathrm{n}=10)$ & Combined $(\mathrm{n}=20)$ & $P U(\mathrm{n}=12)$ & No $P U(\mathrm{n}=12)$ & Combined $(\mathrm{n}=24)$ \\
\hline $\begin{array}{l}\text { Total acute LOS, } \\
\text { mean (SD) }\end{array}$ & $21.8(8.8)$ & $15.0(5.9)$ & $18.4(8.1)$ & $49.3(29.2)$ & $33.5(18.6)$ & $41.4(25.3)$ \\
\hline $\begin{array}{l}\text { Total hospital } \\
\text { cost, mean (SD) }\end{array}$ & $\$ 23,066(\$ 10,155)$ & $\$ 15,276(\$ 5,940)$ & $\$ 19,171(\$ 9,030)$ & $\$ 59,185(\$ 38,112)$ & $\$ 40,427(\$ 24,382)$ & $\$ 49,806(\$ 32,723)$ \\
\hline \multicolumn{7}{|c|}{ Estimated mean of differences } \\
\hline $\begin{array}{l}\text { LOS, mean } \\
\quad(\mathrm{SD} ; 95 \% \mathrm{CI})\end{array}$ & \multicolumn{3}{|c|}{$6.8(5.0 ; 3.2$ to 10.4$)$} & \multicolumn{3}{|c|}{$15.8(19.9 ; 3.1$ to 28.4$)$} \\
\hline $\begin{array}{l}\text { Hospital cost; mean } \\
\quad(\mathrm{SD} ; 95 \% \mathrm{CI})\end{array}$ & \multicolumn{3}{|c|}{$\$ 7,790(\$ 6,267 ; \$ 3,307$ to $\$ 12,273)$} & \multicolumn{3}{|c|}{$\mathbf{\$ 1 8 , 7 5 8}(\$ 27,574 ; \$ 1,239$ to $\$ 36,277)$} \\
\hline
\end{tabular}

UTI, urinary tract infection; PU, pressure ulceration; LOS, length of stay in days; SD, standard deviation; CI, confidence interval. 
accounting for $95 \%$ of UTI in a previous analysis of an acute SCI population in Ontario, Canada (\$6371). ${ }^{30}$ The estimated cost of UTI in this case series is also within the range of costs attributed to minor hospital- and community-acquired genitourinary complications in general patient populations. ${ }^{55-57}$ In comparison, costs attributed to presumably more severe UTI in alternative patient populations are generally higher. ${ }^{2,16,48,58-64}$ The incremental cost of "clinically significant" hospital-acquired UTI in complex medical and surgical admissions in Ontario, Canada, for example, is reported to be $\$ 23,667$. $^{48}$ Similarly, in two Australia SCI populations, hospitalacquired UTI reportedly added $\$ 24,569$ and community-acquired UTI severe enough to result in hospitalization added $\$ 16,354$ to the average costs of care. ${ }^{16,64}$

The range in reported costs of PU is even greater than the range in UTI. Average costs of PU in general inpatient populations range from $\$ 2832$ to $\$ 54,062,{ }^{46-48,56,57,59-61,65-87}$ and costs of PU in SCI populations range from $\$ 18,533$ to $\$ 104,135$. $^{2,16,58,62,64,34,88-93}$ The range is expected to reflect demographic and geographic differences in the population being studied as well as associated differences in the severity of PU in the study population. The range may also reflect differences in the research or costing methodologies, observation period, products and services used to manage or treat $\mathrm{PU}$, and duration of PU treatment. The excess cost of minor PU in the current case series $(\$ 18,758)$ is consistent with the mean hospital cost of PU in a population of SCI admissions in Australia $(\$ 18,533) .{ }^{16}$ It is not surprising that the result of the PU analysis is at the low end of the range in the reported average costs of PU in $\mathrm{SCI}$ populations, as, all else equal, the resources needed to manage a minor PU are expected to be less than the resources needed to treat a severe PU in an acute SCI admission and/or a PU severe enough to result in the hospitalization of a community-dwelling person with SCI.

In terms of the association between PU severity and cost, a recent cost analysis of hospital-acquired PU experienced by elderly patients in Ontario, Canada, revealed that NPUAP category II, III, and IV PU added on average $\$ 43,782, \$ 68,090$, and $\$ 90,026$ to hospital costs, respectively. ${ }^{86}$ The importance of PU severity as a determinate of cost is echoed by analyses in alternative patient populations. ${ }^{48,68,71,87,94-99}$ Moreover, the cost to treat PU in any one person may differ significantly from the mean or expected cost of PU, as demonstrated by the range in per patient costs for PU resulting in hospitalization in Ontario, Canada (less than $\$ 1500$ to more than $\$ 440,000),{ }^{100}$ and by a detailed case study of an individual with SCI in the United States describing PU-related costs of more than $\$ 350,000$. $^{101}$

The exclusion or inclusion of a single individual with relatively severe PU has the potential to significantly affect the estimated average cost. In this analysis, inclusion of the excluded pair in which the PU was described as a complication necessitating invasive or complex treatment would have resulted in an $87 \%$ increase in the estimated average excess cost of PU (from $\$ 18,758$ to $\$ 35,042$ ). Exclusion limited the PU cost analysis to relatively minor complications; however, if the severity distribution in the initial series of paired participants experiencing PU during acute SCI admission (i.e., one hospital-acquired PU necessitating complex treatment for every 12 not requiring complex treatment) reflects the actual distribution of $\mathrm{PU}$ in the specialized spine facility, a more appropriate parameter for economic or decision analytic modeling may be closer to $\$ 35,000$. The possible consequences of using a parameter such as the expected cost of PU in a comparative economic model that does not consider the problem with respect to the population of interest and the severity of the problem extends beyond misinformed decisions concerning the management of UTI and PU in acute SCI care. Therefore, the influence of severity on the cost of secondary complications including UTI and PU deserves further consideration.

Because the results of economic and decision analytic models depend on parameter inputs, it is essential that inputs such as the cost of UTI and PU across all phases in the SCI care continuum represent expected costs in the target population. Evidence from SCI populations suggests higher expected cost of $\mathrm{PU}$ presenting in the community phase of SCI care compared with the acute phase of SCI care. ${ }^{64,34}$ In an Australia SCI population, the average cost of hospitalization because of PU within two years of SCI is estimated to be $\$ 25,994 .{ }^{64}$ Similarly, the average cost attributed to PU in a population of community-dwelling individuals with SCI in Ontario, Canada, is estimated to be $\$ 4797$ per month or $\$ 57,564$ over a conservative seven month recording period. ${ }^{34}$ In a U.S. population of community-dwelling persons with SCI served by the Veterans Health Administration, the estimated excess cost of PU over a 12 month observation period is nearly $\$ 80,000 .{ }^{93}$

The variation in existing estimates of the cost of secondary complications of SCI across the care continuum may be explained by a trend in the expected cost of complications in patients presenting at different time points in the SCI care continuum along which distributional discrepancies in the severity of hospital- and community-acquired complications exist. Therefore, in modeling the economic costs and consequences of possible solutions to the burden of UTI, PU, or other secondary complications, the distinction between hospital- and community-acquired complications and/or the severity distribution and associated risk factors are important considerations for the assessment and comparison of solutions to the burden at different points in the SCI care continuum.

\section{Implications}

Although the evidence is limited, what is known about the burden of UTI and PU suggests a need and opportunity for innovation in the prevention and management of secondary complications across the SCI care continuum. Because of the small number of observations, statistical significance was not assessed in the case series; however, the excess costs of UTI $(\$ 7790)$ and PU $(\$ 18,758)$ are considerable in comparison to the estimated mean acute SCI admission costs for the No Complication Group $(\$ 15,276)$ and the No PU Group $(\$ 40,427)$, representing an addition of $51 \%$ and $46 \%$ to acute admission costs, respectively.

Having evidence of the average cost of a particular secondary complication alone is not sufficient to help decision makers decide what to do about the problem. In-depth assessment of the extent of the problem in acute SCI admissions, which would include factors such as the size of the target population, the influence of acute complication experiences on the risk of subsequent complications, and the cost of possible solutions is necessary to support consideration of relevant solutions. As a simple example, if one assumes that 20 in every 100 acute SCI admissions will experience PU costing approximately $\$ 19,000$, the expected cost for 100 admissions would be $\$ 380,000$. If an intervention that prevented $50 \%$ of PU occurrences could be offered at a cost of $\$ 1900$ per person, it may be justified from a narrow perspective. Further effort to determine the burden (human and economic cost) of complications in the SCI acute, rehabilitation, and community phase of care, as well as the effectiveness of possible solutions, however, is necessary to better inform the supply of solutions across the continuum of SCI care. 


\section{Limitations}

Although case series participants were selected from a larger population of consecutive admissions to the study site, the case series population is not necessarily representative of the larger acute SCI population or the SCI population experiencing acute complications. For reasons discussed, the UTI cost analysis was limited to participants with no other documented acute complications. The results of the UTI and PU cost analyses reflect the excess hospital cost of relatively minor UTI and PU in acute traumatic SCI admissions to a specialized spine facility, which may limit generalizability to alternative populations. Our results, however, are within the range of earlier analyses, adding increased confidence to the generalizability of evidence established in alternative general patient and SCI populations.

The assumption is that documented UTI and PU led to excess days in hospital; but given that the time of complication onset was not considered, it is possible that unobserved factors led to the extended LOS, which may have led to documented secondary complications. In addition, because matching was based on a limited number of observed demographic and SCI characteristics, the estimated excess cost of UTI and PU may reflect unobserved factors. Another notable limitation is that the cases series was restricted to participants with relatively minor UTI and PU, and stratification by UTI and PU severity was not possible. In general, the case series sample size restriction prevented other important subgroup analyses, added to the variability in terms of the difference in estimated acute SCI hospital cost between pairs, and increased the influence that a single difference may have on the estimated mean of the differences.

Although this analysis made effective use of the limited costing information provided by the study site, the matched-case control methodology employed has certain limitations. ${ }^{102}$ In particular, the results are only as good as the matches or the matching criteria. Although the available data were not appropriate in this case series, activity-based or bottom-up cost analyses that require a review of sufficiently detailed resource utilization or costing information and subsequent determination of relevant resources or expenditures at the participant level may have certain advantages. One advantage may be the avoidance of bias in cost estimation due to matching on a limited number of observed characteristics, however, the choice of methodology depends on the data available.

The exclusion of other costs to affected individuals, their family members, and healthcare systems is a limitation that is expected to have contributed to the conservative nature of the results. With respect to the acute hospital cost data that were available, the study site does not maintain a case-costing system, and the basic costing formula applied by hospital financial planning and business support is expected to have resulted in conservative estimates of the total acute SCI admission costs. Because the costing formula was applied to selected participants with and without UTI and PU for the respective cost analyses, however, the effect of the basic formula on the estimated excess burden of UTI and PU is unclear.

\section{Next steps}

The Access to Care and Timing (ACT) simulation model for SCI care, ${ }^{103,104}$ described in the current focus issue, ${ }^{105}$ is one example of a decision analytic model that allows for comparative analyses of interventions in one phase of care on the entire continuum of care. The results of the case series and discussion will support application of the ACT model to access possible solutions to the burden of UTI and PU in the traumatic SCI population. The presentation of results will also support the evaluation of the benefits and costs of alternative solutions more broadly.
As per the Rick Hansen Institute's Health Economics Agenda for SCI Research in Canada, ${ }^{106}$ however, evidence of the burden of secondary complications of SCI and knowledge of the structural relationship between the burden and possible solutions to the burden at different points in the SCI care continuum are necessary to ensure possible solutions receive due consideration. Further consideration of the collection, organization, and provision of costing and resource utilization information across the SCI continuum of care will continue to support the establishment of evidence or appropriate inputs for decision analytic modeling and comparative economics analyses.

In the development of a whole system model to better inform clinical practice and resource allocation decisions ultimately affecting people sustaining a SCI in Canada, further estimation and consideration of the human and economic costs associated with common secondary complications beyond the acute phase and across the SCI care continuum are critical. The lessoned learned through this exploratory case series analysis in terms of the limitations of costing information available through the study site for cost analysis in the acute SCI population will inform necessary next steps.

\section{Conclusion}

The case series analysis provided conservative estimates of the excess or incremental costs of UTI and PU in SCI admissions to a Level I specialized spine facility, establishing evidence needed to enhance the breadth, quality, and relevancy of information from future economic analyses and decision analytic modeling efforts in SCI. Further understanding of the burden of secondary complications of SCI across the continuum of care, as well as the alternative solutions will encourage the establishment of comparative economic evidence to better inform clinical practice and health policy decisions involving such risk versus reward and value for money considerations in SCI in Canada and beyond.

\section{Acknowledgments}

The authors thank the Vancouver Spine Research Program (Juliet Batke, Allan Aludino); the Rick Hansen Institute RHSCIR Team (Suzanne Humphreys, Daniel Rogers, Kristen Walden, Jayson Shurgold, Jessica Eapen, Jerome Buenaventura, Tova Plashkes, Arlene Aspinall, Cynthia Morin, and Shannon Sproule); all members of the Vancouver Spine Surgery Institute; and the Vancouver Coastal Health, Financial Planning and Business Support for their contribution to the study.

This study was supported by financial contributions from the Rick Hansen Institute, the Ontario Neurotrauma Foundation, and the Government of Canada through Health Canada and Western Economic Diversification Canada.

\section{Author Disclosure Statement}

No competing financial interests exist.

\section{References}

1. Anson, C.A., and Shepherd, C. (1996). Incidence of secondary complications in spinal cord injury. Int. J. Rehabil. Res. 17, 55-66.

2. DeVivo, M., and Farris, V. (2011). Causes and costs of unplanned hospitalizations among persons with spinal cord injury. Top. Spinal Cord Inj. Rehabil. 16, 53-61.

3. DeJong, G., Tian, W., Hsieh, C.H., Junn, C., Karam, C., Ballard, P.H., Smout, R.J., Horn, S.D., Zanca, J.M., Heinemann, A.W., Hammond, F.M., and Backus, D. (2013). Rehospitalization in the first year of traumatic spinal cord injury after discharge from medical rehabilitation. Arch. Phys. Med. Rehabil. 94, Suppl 4, S87-S97. 
4. Guilcher, S.J., Craven, B.C., Lemieux-Charles, L., Casciaro, T., McColl, M.A., and Jaglal, S.B. (2013). Secondary health conditions and spinal cord injury: an uphill battle in the journey of care. Disabil. Rehabil. 35, 894-906.

5. Hitzig, S.L., Tonack, M., Campbell, K., McGillivray, C.F., Boschen, K., Richards, K., and Craven, B.C. (2008). Secondary health complications in an aging Canadian spinal cord injury sample. Am. J. Phys. Med. Rehabil. 87, 545-555.

6. Krause, J.S. (1996). Secondary conditions and spinal cord injury: A model for prediction and prevention. Top. Spinal Cord Inj. Rehabil. 2, 58-70.

7. Jensen, M.P., Truitt, A.R., Schomer, K.G., Yorkston, K.M., Baylor, C., and Molton, I.R. (2013). Frequency and age effects of secondary health conditions in individuals with spinal cord injury: a scoping review. Spinal Cord 51, 882-892.

8. Johnson, R.L., Gerhart, K.A., McCray, J., Menconi, J.C., and Whiteneck, G.G. (1998). Secondary conditions following spinal cord injury in a population-based sample. Spinal Cord 36, 45-50.

9. Middleton, J.W., Lim, K., Taylor, L., Soden, R., and Rutkowski, S. (2004). Patterns of morbidity and rehospitalisation following spinal cord injury. Spinal Cord 42, 359-367.

10. Noreau, L., Proulx, P., Gagnon, L., Drolet, M., and Laramee, M. (2000). Secondary impairments after spinal cord injury: a populationbased study. Am. J. Phys. Med. Rehabil. 79, 526-535.

11. Paker, N., Soy, D., Kesiktas, N., Nur Bardak, A., Erbil, M., Erspy, S., and Yilmaz, H. (2006). Reasons for rehospitalization in patients with spinal cord injury : 5 years' experience. Int. J. Rehabil. Res. 29, 71-76.

12. Savic, G., Short, D.J., Weitzenkamp, D., Charlifue, S., and Gardner, B.P. (2000). Hospital readmissions in people with chronic spinal cord injury. Spinal Cord 38, 371-377.

13. Aito, S. (2003). Complications during the acute phase of traumatic spinal cord lesions. Spinal Cord 41, 629-635.

14. Dryden, D.M., Saunders, L.D., Rowe, B.H., May, L., Yiannakoulias, N., Svenson, L.W., Schopflocher, D.P., and Voaklander, D.C. (2004). Utilization of health services following spinal cord injury: a 6-year follow-up study. Spinal Cord 42, 513-525.

15. Fletcher, D.J., Taddonio, R.F., Byrne, D.W., Wexler, L.M., Cayten, G., Nealon, S.M., and Carson, W. (1995). Incidence of acute care complictions in vertebral column fracture patients with and without spinal cord injury. Spine 20, 1136-1146.

16. New, P.W., and Jackson, T. (2010). The costs and adverse events associated with hospitalization of patients with spinal cord injury in Victoria, Australia. Spine 35, 796-802.

17. Krassioukov, A.V, Furlan, J.C., and Fehlings, M.G. (2003). Medical co-morbidities, secondary complications, and mortality in elderly with acute spinal cord injury. J. Neurotrauma 20, 391-399.

18. Street, J.T., Noonan, V.K., Cheung, A., Fisher, C.G., and Dvorak, M.F (2015). Incidence of acute care adverse events and long-term healthrelated quality of life in patients with TSCI. Spine J. 15, 923-932.

19. Street, J.T., Thorogood, N.P., Cheung, A., Noonan, V.K., Chen, J., Fisher, C.G., and Dvorak, M.F. (2013). Use of the Spine Adverse Events Severity System (SAVES) in patients with traumatic spinal cord injury. A comparison with institutional ICD-10 coding for the identification of acute care adverse events. Spinal Cord 51, 472-476.

20. Chen, Y., Devivo, M.J., and Jackson, A.B. (2005). Pressure ulcer prevalence in people with spinal cord injury: age-period-duration effects. Arch. Phys. Med. Rehabil. 86, 1208-1213.

21. Gunnewicht, B.R. (1995). Pressure sores in patients with acute spinal cord injury. J Wound Care 4, 452-454.

22. Henzel, K., Bogie, K., Guihan, M., and Ho, C.H. (2011). Pressure ulcer management and research priorities for patients with spinal cord injury: Consensus opinion from SCI QUERI Expert Panel on Pressure Ulcer Research Implementation. J. Rehabil. Res. Dev. 48, xi-xxxi.

23. Houghton, P., Campbell, K., and CPG Panel. (2013). Canadian Best Practice Guidelines for the Prevention and Management of Pressure Ulcers in People with Spinal Cord Injury. A Resource Handbook for Clinicians. ONF Available at: onf.org/system/attachments/168/original/Pressure_Ulcers_Best_Practice_Guideline_Final_web4.pdf. Accessed August 25, 2017.

24. Niazi, Z.B., Salzberg, A.C., Byrne, D.W., and Viehbeck, M. (1997). Recurrence of initial pressure ulcer in persons with spinal cord injury. Adv. Wound Care 10, 38-42.

25. Kruger, E., Pires, M., Ngann, Y., Sterling, M., and Rubayi, S. (2013) Comprehensive management of pressure ulcers in spinal cord injury: current concepts and future trends. J. Spinal Cord Med. 36, 572-585.
26. Lala, D., Dumont, F.S., Leblond, J., Houghton, P.E., and Noreau, L. (2014). Impact of pressure ulcers on individuals living with a spinal cord injury. Arch. Phys. Med. Rehabil. 95, 2312-2319.

27. Marion, T.E., Rivers, C.S., Kuerban, D., Cheng, C.L., Fallah, N., Batke, J., Dvorak, M.F., Fisher, C.G., Kwon, B.K., Noonan, V.K., and Street, J.T. (2017). Previously identified common post-injury adverse events in traumatic spinal cord injury-validation of existing literature and relation to selected potentially modifiable comorbidities: a prospective Canadian cohort study. J Neurotrauma. Epub ahead of print.

28. Campbell, P.G., Malone, J., Yadla, S., Maltenfort, M.G., Harrop, J.S., Sharan, A.D., and Ratliff, J.K. (2010). Early complications related to approach in thoracic and lumbar spine surgery: a single center prospective study. World Neurosurg. 73, 395-401.

29. Dea, N., Versteeg, A., Fisher, C., Kelly, A., Hartig, D., Boyd, M., Paquette, S., Kwon, B.K., Dvorak, M., and Street, J. (2014). Adverse events in emergency oncological spine surgery: a prospective analysis. J. Neurosurg. Spine 21, 698-703.

30. Hellsten, E.K., Hanbidge, M., Manos, A.N., Lewis, S.J., Massicotte, E.M., Fehlings, M.G., Coyte, P.C., and Rampersaud, Y.R. (2013). An economic evaluation of perioperative adverse events associated with spinal surgery. Spine J. 13, 44-53.

31. Kelly, A.M., Batke, J.N., Dea, N., Hartig, D.P., Fisher, C.G., and Street, J.T. (2014). Prospective analysis of adverse events in surgical treatment of degenerative spondylolisthesis. Spine J. 14, 2905-2910.

32. Street, J.T., Lenehan, B.J., DiPaola, C.P., Boyd, M.D., Kwon, B.K., Paquette, S.J., Dvorak, M.F., Rampersaud, Y.R., and Fisher, C.G. (2012). Morbidity and mortality of major adult spinal surgery. A prospective cohort analysis of 942 consecutive patients. Spine J. 12, 22-34.

33. Zakrasek, E.C., Creasey, G., and Crew, J.D. (2015). Pressure ulcers in people with spinal cord injury in developing nations. Spinal Cord $53,7-13$.

34. Chan, B.C., Nanwa, N., Mittmann, N., Bryant, D., Coyte, P.C., and Houghton, P.E. (2013). The average cost of pressure ulcer management in a community dwelling spinal cord injury population. Int. Wound J. 10, 431-440.

35. Anderson, G.F., Reinhardt, U.E., Hussey, P.S., and Petrosyan, V. (2003). It's the prices, stupid: why the United States is so different from other countries. Health Aff. 22, 89-105.

36. Reinhardt, U. (2008). Why Does U.S. Health Care Cost So Much? (Part I). New York Times. Available at: economix.blogs.nytimes .com/2008/11/14/why-does-us-health-care-cost-so-much-part-i/?_r $=1$. Accessed August 25, 2017

37. Reinhardt, U. (2008). Why does U.S. health care cost so much? (Part II: Indefensible administrative costs). New York Times. Available at: economix.blogs.nytimes.com/2008/11/21/why-does-us-health-care-costso-much-part-ii-indefensible-administrative-costs/. Accessed August 25, 2017.

38. Chan, B., McIntyre, A., Mittmann, N., Teasell, R.R., and Wolfe, D.D. (2014). Economic Evaluation of Spinal Cord Injury. 1-21. Available at: scireproject.com. Accessed August 25, 2017.

39. Noonan, V., Kwon, B., Soril, L., Fehlings, M., Hurlbert, R., Townson, A., Johnson, M., and Dvorak, M.; RHSCIR Network. (2012). The Rick Hansen Spinal Cord Injury Registry (RHSCIR): a national patient-registry. Spinal Cord 50, 22-27.

40. Noonan, V.K., Thorogood, N.P., Joshi, P.B., Fehlings, M.G., Craven, B.C., Linassi, G., Fourney, D.R., Kwon, B.K., Bailey, C.S., Tsai, E.C., Drew, B.M., Ahn, H., Tsui, D., and Dvorak, M.F. (2013). Meeting the privacy requirements for the development of a multi-centre patient registry in Canada: the Rick Hansen Spinal Cord Injury Registry. Healthc. Policy 8, 87-99.

41. Middleton, P.M., Davies, S.R., Anand, S., Reinten-Reynolds, T., Marial, O., and Middleton, J.W. (2012). The pre-hospital epidemiology and management of spinal cord injuries in New South Wales: 2004-2008. Injury 43, 480-485.

42. DeVivo, M.J., Kartus, P.L., Stover, S.L., and Fine, P.R. (1990). Benefits of early admission to an organised spinal cord injury care system. Paraplegia 28, 545-555.

43. Waring, W.P., Biering-Sorensen, F., Burns, S., Donovan, W., Graves, D., Jha, A., Jones, L., Kirshblum, S., Marino, R., Mulcahey, M.J., Reeves, R., Scelza, W.M., Schmidt-Read, M., and Stein, A. (2010). 2009 review and revisions of the international standards for the neurological classification of spinal cord injury. J. Spinal Cord Med. $33,346-352$. 
44. Glennie, R.A., Noonan, V.K., Fallah, N., Park, S.E., Thorogood, N.P., Cheung, A., Fisher, C.G., Dvorak, M.F., and Street, J.T. (2014). Reliability of the spine adverse events severity system (SAVES) for individuals with traumatic spinal cord injury. Spinal Cord 52, 758-763.

45. Rampersaud, Y.R., Neary, M.A., and White, K. (2010). Spine adverse events severity system: content validation and interobserver reliability assessment. Spine 35, 790-795.

46. Encinosa, W.E., and Hellinger, F.J. (2008). The impact of medical errors on ninety-day costs and outcomes: an examination of surgical patients. Health Serv. Res. 43, 2067-2085.

47. Rivard, P.E., Luther, S.L., Christiansen, C.L., Shibei Zhao, Loveland, S., Elixhauser, A., Romano, P.S., and Rosen, A.K. (2008). Using patient safety indicators to estimate the impact of potential adverse events on outcomes. Med. Care Res. Rev. 65, 67-87.

48. Wardle, G., Wodchis, W.P., Laporte, A., Anderson, G.M., and Ross Baker, G. (2012). The sensitivity of adverse event cost estimates to diagnostic coding error. Health Serv. Res. 47, 984-1007.

49. Zhan, C., and Miller, M.R. (2013). Excess length of stay, charges, and mortality attributable to medical injuries during hospitalization. JAMA 290, 1868-1874.

50. StataCorp. (2013). Stata Statistical Software: Release 13. College Station, TX: StataCorp LP.

51. Organisation for Economic Co-operation and Development. (2013). Purchasing power partities and exchange rates. StatExtracts. OECD.

52. Statistics Canada. (2014). Table 326-0020. Consumer price index (CPI), CANSIM (database).

53. Austin, P.C. (2011). An introduction to propensity score methods for reducing the effects of confounding in observational studies. Multivariate Behav. Res. 46, 399-424.

54. National Pressure Ulcer Advisory Panel, European Pressure Ulcer Advisory Panel, and Pan Pacific Pressure Injury Alliance. (2014) Prevention and Treatment of Pressure Ulcers: Quick Reference Guide, 2nd ed. Perth, Australia: Cambridge Media.

55. Hoonhout, L.H., de Bruijne, M.C., Wagner, C., Zegers, M., Waaijman, R., Spreeuwenberg, P., Asscheman, H., van der Wal, G., and van Tulder, M.W. (2009). Direct medical costs of adverse events in Dutch hospitals. BMC Health Serv. Res. 9, 27.

56. Canadian Institute for Health Information. (2008). The Cost of Acute Care Hospital Stays by Medical Condition in Canada, 2004-2005. Ottawa, ON.

57. Jackson, T., Nghiem, H.S., Rowell, D., Jorm, C., and Wakefield, J. (2011). Marginal costs of hospital-acquired conditions: information for priority-setting for patient safety programmes and research. J. Health Serv. Res. Policy 16, 141-146.

58. Young, A., Webster, B., Giunti, G., Pransky, G., and Nesathurai, S. (2006). Rehospitalization following compensable work-related tetraplegia. Spinal Cord 44, 374-382.

59. Carey, K., and Stefos, T. (2011). Measuring the cost of hospital adverse patient safety events. Health Econ 20, 1417-1430.

60. Carey, K., Stefos, T., Shibei Zhao, Borzecki, A.M., and Rosen, A.K. (2011). Excess costs attributable to postoperative complications. Med. Care Res. Rev. 68, 490-503.

61. Shreve, J., van Den Bos, J., Gray, T., Halford, M., Rustagi, K., and Ziemkiewicz, E. (2010). The Economic Measurement of Medical Errors. The Society of Actuaries:Schaumberg, IL.

62. DeVivo, M.J. (1998). Rehospitalization costs of individuals with spinal cord injury. Research update. U Spain Rehabilitation Center: Birmingham, AL.

63. Morse, B.C., Boland, B.N., Blackhurst, D.W., and Roettger, R.H. (2010). Analysis of Centers for Medicaid and Medicare Services "never events" in elderly patients undergoing bowel operations. Am. Surg. 76, 841-845.

64. Gabbe, B.J., and Nunn, A. (2016). Profile and costs of secondary conditions resulting in emergency department presentations and readmission to hospital following traumatic spinal cord injury. Injury 47, 1847-1855.

65. Allman, R.M., Goode, P.S., Burst, N., Bartolucci, A.A., and Thomas, D.R. (1999). Pressure ulcers, hospital complications and disease severity: Impact on hospital costs and length of stay. Adv. Wound Care $12,22-30$.

66. Alterescu, V. (1989). The financial costs of inpatient pressure ulcers to an acute care facility. Decubitus 2, 14-23.

67. Beckrich, K., and Aronovitch, S.A. (1999). Hospital-acquired pressure ulcers: a comparison of costs in medical vs. surgical patients. Nurs. Econ. 17, 263-271.
68. Bennett, G., Dealey, C., and Posnett, J. (2004). The cost of pressure ulcers in the UK. Age Ageing 33, 230-235.

69. Centers for Medicare and Medicaid Services. (2008). Medicare program: proposed changes to the hospital inpatient prospective payment systems and fiscal year 2009 rates; proposed changes to disclosure of physician ownership in hospitals and physician selfreferral rules; proposed collection of information. Fed. Regist. 73 , 23528-938.

70. Dall, T.M., Chen, Y.J., Seifert, R.F., Maddox, P.J., and Hogan, P.F. (2009). The economic value of professional nursing. Med. Care 47, 97-104.

71. Dealey, C., Posnett, J., and Walker, A. (2012). The cost of pressure ulcers in the United Kingdom. J. Wound Care 21, 261-266.

72. Fuller, R.L., McCullough, E.C., Bao, M.Z., and Averill, R.F. (2009). Estimating the costs of potentially preventable hospital acquired complications. Health Care Financ. Rev. 30, 17-32.

73. Graves, N., Birrell, F.A., and Whitby, M. (2005). Modeling the economic losses from pressure ulcers among hospitalized patients in Australia. Wound Repair Regen. 13, 462-467.

74. Graves, N., and Zheng, H. (2014). Modelling the direct health care costs of chronic wounds in Australia. Wound Pract. Res. 22, 462-467.

75. Jackson, T., Fong, A., Liu, M., Murray, K., Walz, L., Houston, C., Walker, K., and Dean, S. (2011). Incremental costs of hospitalacquired complications in Alberta, Canada. BMC Health Serv. Res. $11, \mathrm{~A} 15$.

76. Kuhn, B.A., and Coulter, S.J. (1992). Balancing the pressure ulcer cost and quality equation. Nurs. Econ. 10, 353-359.

77. Kumar, R.N., Gupchup, G.V, Dodd, M.A., Shah, B., Iskedjian, M., Einarson, T.R., and Raisch, D.W. (2004). Direct health care costs of 4 common skin ulcers in New Mexico Medicaid fee-for-service patients. Adv. Skin Wound Care 17, 143-149.

78. Lapsley, H.M., and Vogels, R. (1996). Cost and prevention of pressure ulcers in an acute teaching hospital. Int. J. Qual. Heal. Care 8, 61-66.

79. Miller, H., and DeLozier, J. (1994). Cost Implications of the Pressure Ulcer Treatment Guideline. Agency for Health Care Policy and Research, Public Health Service: Rockville, MD.

80. Pappas, S.H. (2008). The cost of nurse-sensitive adverse events. J. Nurs. Adm. 38, 230-236.

81. Plotzke, M., Subramanian, R., and Olsho, L. (2011). Cost reductions associated with declines in pressure ulcers at MHA hospitals. Massachusetts Hospital Association: Burlington, MA.

82. Russo, C.A., and Elixhauser, A. (2006). Hospitalizations Related to Pressure Sores, 2003. Healthcare cost and utilization projects Statistical Brief \# 3. Agency for Healthcare Research and Quality: Rockville, MD.

83. Russo, A., Steiner, C., and Spector, W. (2008). Hospitalizations related to pressure ulcers among adults 18 years and older, 2006 Healthcare cost and utilization project (HCUP) Statistical Brief \# 64. Agency for Healthcare Research and Quality: Rockville, MD.

84. Sanders, W., and Allen, R.D. (2006). Pressure management in the operating room: Problems and solutions. Manag. Infect. Control 6, $63-72$.

85. Xakellis, G.C., and Frantz, R. (1996). The cost of healing pressure ulcers across multiple health care settings. Adv. Wound Care 9, 18-22.

86. Chan, B., Ieraci, L., Mitsakakis, N., Pham, B., and Krahn, M. (2013). Net costs of hospital-acquired and pre-admission PUs among older people hospitalised in Ontario. J. Wound Care 22, 341-346.

87. Pham, B., Teague, L., Mahoney, J., Goodman, L., Paulden, M., Poss, J., Li, J., Sikich, N.J., Lourenco, R., Ieraci, L., Carcone, S., and Krahn, M. (2011). Support surfaces for intraoperative prevention of pressure ulcers in patients undergoing surgery: a cost-effectiveness analysis. Surgery $150,122-132$.

88. Allen, J., and Houghton, P.E. (2004). A case study for electrical stimulation on a stage III pressure ulcer. Wound Care Canada 2, 34-36.

89. Jones, M.L., Mathewson, C.S., Adkins, V.K., and Ayllon, T. (2003). Use of behavioral contingencies to promote prevention of recurrent pressure ulcers. Arch. Phys. Med. Rehabil. 84, 796-802.

90. Johnson, R.L., Brooks, C., and Whiteneck, G.G. (1996). Cost of traumatic spinal cord injury in a population-based registry. Spinal Cord 34 , 470-480.

91. Mittmann, N., Chan, B.C., Craven, B.C., Isogai, P.K., and Houghton, P. (2011). Evaluation of the cost-effectiveness of electrical stimulation therapy for pressure ulcers in spinal cord injury. Arch. Phys. Med. Rehabil. 92, 866-872. 
92. St. Andre, J.R., Smith, B.M., Stroupe, K.T., Burns, S.P., Evans, C.T., Ripley, D.C., Li, K., Huo, Z., Hogan, T.P., and Weaver, F.M. (2011) A comparison of costs and health care utilization for veterans with traumatic and nontraumatic spinal cord injury. Top. Spinal Cord Inj. Rehabil. 16, 27-42.

93. Stroupe, K.T., Manheim, L., Evans, C.T., Guihan, M., Ho, C., Li, K. Cowper-Ripley, D., Hogan, T.P., St. Andre, J.R., Huo, Z., and Smith, B.M. (2011). Cost of treating pressure ulcers for veterans with spinal cord injury. Top. Spinal Cord Inj. Rehabil. 16, 62-73.

94. Frantz, R.A. (1989). Pressure ulcer costs in long-term care. Decubitus 2, 56-57.

95. Padula, W.V, Mishra, M.K., Makic, M.B., and Sullivan, P.W. (2011). Improving the quality of pressure ulcer care with prevention: a costeffectiveness analysis. Med. Care 49, 385-392.

96. Schuurman, J., Schoonhoven, L., Defloor, T., van Engelshoven, I., van Ramshorst, B., and Buskens, E. (2009). Economic evaluation of pressure ulcer care: a cost minimization analysis of preventive strategies. Nurs. Econ. 27, 390-415.

97. Brem, H., Maggi, J., Nierman, D., Rolnitzky, L., Bell, D., Rennert, R., Golinko, M., Yan, A., Lyder, C., and Vladeck, B. (2011). High cost of stage IV pressure ulcers. Am. J. Surg. 200, 473-477.

98. Gethin, G., O'Brien, J., and Moore, Z. (2005). Estimating costs of pressure area management based on a survey of ulcer care in one Irish hospital. J. Wound Care 14, 162-165.

99. Hibbs, P. (1988). The economics of pressure ulcer prevention. Decubitus $1,32-38$.

100. Ontario Case Costing Initiative (OCCI). (2010). OCCI Costing Analysis Tool (CAT). Available at: www.occp.com. Accessed August 25, 2017.

101. Schessel, E.S., Ger, R., and Oddsen, R. (2012). The costs and outcomes of treating a deep pressure ulcer in a patient with quadriplegia. Ostomy Wound Manage. 58, 41-46.
102. Rose, S., and Laan, M.J. van der. (2009). Why match? Investigating matched case-control study designs with causal effect estimation. Int. J. Biostat. 5, Article 1

103. Santos, A., Gurling, J., Dvorak, M.F., Noonan, V.K., Fehlings, M.G., Burns, A.S., Lewis, R., Soril, L., Fallah, N., Street, J.T., Bélanger, L. Townson, A., Liang, L., and Atkins, D. (2013). Modeling the patien journey from injury to community reintegration for persons with acute traumatic spinal cord injury in a Canadian centre. PLoS One 8 , e72552.

104. Atkins, D., Noonan, V.K., Santos, A., Lewis, R., Fehlings, M., Burns, A., and Dvorak, M. (2012). Secondary complications in SCI across the continuum: Using operations research to predict the impact and optimize management strategies. Top. Spinal Cord Inj. Rehabil. 18 57-66.

105. Fehlings, M.G., Noonan, V., Atkins, D., Burns, A.S., Cheng, C.L., Singh, A., and Dvorak, M.F. (2017). Optimizing clinical decision making in acute traumatic spinal cord injury. J. Neurotrauma. Epub ahead of print.

106. White, B.A. (2016). Health Economics: Agenda for SCI Research in Canada. Rick Hansen Institute. Available at: www.rickhanseninstitute. org/images/stories/Article_PDFs/Health-Economics-report.pdf. Accessed August 25, 2017.

Address correspondence to:

Barry A.B. White, MPP

Rick Hansen Institute

6400-818 West 10th Avenue

Vancouver, British Columbia

V5Z 1M9 Canada

E-mail: bwhite@rickhanseninstitute.org 